\title{
Additive and nonadditive genetic variation in avian personality traits
}

\author{
K van Oers ${ }^{1,2}$, PJ Drent ${ }^{1}, \mathrm{G}$ de Jong ${ }^{2}$ and $\mathrm{AJ}$ van Noordwijk ${ }^{1}$ \\ ${ }^{1}$ Department of Population Biology of Animals, Netherlands Institute of Ecology (N100-KNAW), PO Box 40, 6666 ZG, Heteren, \\ The Netherlands; ${ }^{2}$ Evolutionary Population Biology, Utrecht University, Padualaan 8, 3584 CH, Utrecht, The Netherlands
}

\begin{abstract}
Individuals of all vertebrate species differ consistently in their reactions to mildly stressful challenges. These typical reactions, described as personalities or coping strategies, have a clear genetic basis, but the structure of their inheritance in natural populations is almost unknown. We carried out a quantitative genetic analysis of two personality traits (exploration and boldness) and the combination of these two traits (early exploratory behaviour). This study was carried out on the lines resulting from a two-directional artificial selection experiment on early exploratory behaviour (EEB) of great tits (Parus major) originating from a wild population. In analyses using the original lines, reciprocal $F_{1}$
\end{abstract}

and reciprocal first backcross generations, additive, dominance, maternal effects ands sex-dependent expression of exploration, boldness and EEB were estimated. Both additive and dominant genetic effects were important determinants of phenotypic variation in exploratory behaviour and boldness. However, no sex-dependent expression was observed in either of these personality traits. These results are discussed with respect to the maintenance of genetic variation in personality traits, and the expected genetic structure of other behavioural and life history traits in general.

Heredity (2004) 93, 496-503. doi:10.1038/sj.hdy.6800530 Published online 28 July 2004

Keywords: Parus major, personalities; exploration; boldness; sex-dependent expression; maternal effects

\section{Introduction}

Classically traits are split up in more or less strict categories: physiological, morphological, behavioural and life-history traits. Morphological and life history traits have had most attention, since they are easily measurable and their variation is very obvious. Morphological traits comprise characteristics that influence the appearance of an individual (eg colour or bone size) where life-history traits are traits that play a direct part in reproduction and survival (eg sex ratio or clutch size; Stearns, 1992)

The strength of the relation between fitness and a particular trait category is often assumed to be negatively correlated with its heritability (Merilä and Sheldon, 2000) since selection is assumed to erode additive genetic variation (Houle, 1992; Stirling et al, 2002). Empirical studies have shown that life-history traits, which one assumes are closely related to fitness, have lower heritabilities than for example, morphological traits (Mousseau and Roff, 1987; Houle, 1992; Merilä and Sheldon, 2000), which seems to confirm this hypothesis. Although behavioural ecologists consider many behavioural traits to be closely related to fitness, the link between fitness and behavioural traits is often unclear (Houle, 1992). A recent study of Stirling et al (2002) showed that heritabilities of behavioural traits are not different from heritabilities of life-history traits, but

Correspondence: K van Oers, Department of Population Biology of Animals, Netherlands Institute of Ecology (N100-KNAW), PO Box 40, 6666 ZG, Heteren, The Netherlands. E-mail: k.vanoers@nioo.knaw.nl Received 12 February 2003; accepted 20 May 2004; published online 28 July 2004 smaller than heritabilities of morphological traits, suggesting that behavioural traits are as closely related to fitness as life-history traits. One major problem is that these low heritabilities could be caused by an erosion of genetic variation, by selection (elimination-selection hypothesis Houle, 1992) or by a disproportional increase in residual variation (disproportional compounding hypothesis, Houle, 1992; Merilä and Sheldon, 2000; Stirling et al, 2002). The residual variance equals the remaining variance that cannot be explained by the regression when calculating the heritability (Lynch and Walsh, 1998). In most studies where estimates of the magnitude of components exist, lower heritability is not due to lower genetic variance, but due to a high residual variation.

To get a better understanding of the link between heritabilities and fitness consequences and therefore the evolution of a trait, a good knowledge of the structure of its genetic variation is needed (Van Noordwijk, 1990; Merilä and Sheldon, 1999, 2001; Réale and FestaBianchet, 2000). A major advantage of using behavioural traits for these kind of studies, is the possibility of measuring them relatively early in life. Whereas lifehistory traits are often measurable only later during life, many differences in behavioural traits arise already soon after birth.

Individuals within populations differ consistently in how they react to mildly stressful challenges (Gosling, 2001). Although dependent on the environmental context, the same range of reactions is found independent of sex, age or social status (Wilson et al, 1994). Such behavioural differences are quantified on axes such as the 'big five' (openness to experience, conscientiousness, extraversion, agreeableness and neuroticism) in humans (John, 1990), and aggressiveness (Hessing et al, 1993), 
reactivity (Benus et al, 1991), boldness/shyness (Wilson et al, 1994), temperament (Réale et al, 2000), neophobia (Greenberg and Mettke-Hofmann, 2001) and exploration (Benus et al, 1987) in other animals. Different behavioural, physiological and pharmacological reactions are correlated, indicating that these are fundamental aspects of variation in behavioural organisation. In humans, this is referred to as variation in human personality, in other taxa also as behavioural tendencies, temperaments, syndromes, constructs, styles or strategies (Wilson et al, 1994).

Personality traits are known to influence reproduction, survival and dispersal and therefore fitness (Réale and Festa-Bianchet, 2003; Armitage and Van Vuren, 2003; Dingemanse, 2003). Traditionally, it has been assumed that there is little or no additive genetic variation in traits that influence fitness, as they are supposed to be under strong directional selection (eg Jones, 1987). Quantitative genetic traits are most likely influenced by many loci, with each locus having a small effect on the trait. Therefore, it is important to not consider only additive but also nonadditive sources of phenotypic variation (Falconer and Mackay, 1996), like dominance, genetic maternal effects and sex-dependent expression (Lynch and Walsh, 1998).

In contrast to additive genetic variation, quantitative genetic theory predicts that the relative amount of genetic dominance variation should increase under selection (Mousseau and Roff, 1987; Roff, 1997; Merilä and Sheldon, 1999). This was confirmed in the study of Crnokrak and Roff (1995), who found that levels of dominance variance in life-history traits were higher than those in morphological traits. In contrast, Stirling et al (2002) found in a comparative study that relatively high dominance variation was common in domestic and semi-domestic, but not in natural, populations. Maternal effects are known to be able to play an important role in evolution (Bernardo, 1996; Mousseau and Fox, 1998). Studies on maternal hormones (Schwabl et al, 1997; Eising et al, 2001), on the relation between maternal environment and antibodies (Heeb et al, 1998) and on the influence of females on their offspring sex ratio (Komdeur et al, 1997; Sheldon et al, 1999) show that female birds may control a surprisingly wide range of characteristics of their offspring. Recent theoretical, laboratory work and work in natural populations (McAdam et $a l, 2002)$ has suggested that heritable maternal effects can have important influences on the potential of evolution (Wolf et al, 1998; McAdam et al, 2002). Both in humans and in other animals, sex differences in personality traits are reported (Buirski et al, 1978; Budaev, 1999; Benus, 2001). It is therefore quite possible that the expression of the genes is dependant on the gender of the individual.

In our model species, the great tit Parus major handreared individuals of both sexes consistently differ in the way they explore a novel environment, and these differences are strongly correlated with differences in behaviour towards novel objects (Verbeek et al, 1994; Drent and Marchetti, 1999; Drent et al, 2002). A heritable component was shown to exist for exploration and boldness in a directional selection experiment (Drent et al, 2003) and in a natural population (Dingemanse et al, 2002; Drent et al, 2003). These individual differences in exploration and boldness have predictive value for differences in risk-taking behaviour (Van Oers et al, 2003), aggressiveness (Verbeek et al, 1996), recovery time and behaviour after lost contests (Verbeek et al, 1999), foraging behaviour (Drent and Marchetti, 1999; Marchetti and Drent, 2000) and reactions to stress (Carere et al, 2001; Carere, 2003; Carere and Van Oers, 2003; Van Oers, 2003). With this system, we are able to conduct a quantitative genetic study on natural variation in several correlated behavioural traits.

In this study, we performed a crossing experiment to estimate additive and nonadditive genetic components, maternal effects and sex-dependent expression of exploration and boldness. Great tits of two lines resulting from a two-directional artificial selection experiment for the extremes of the combination of these traits ('fast' and 'slow' explorers; Drent et al, 2003) were crossed to produce hybrid $F_{1}$ and their first backcross generations. By using the two original lines (two groups) and the reciprocals of the $F_{1}$ (two groups) and first-generation backcrosses (four groups), we have phenotypic means of eight groups. This provides enough data to test the adequacy of genetic models of expected group means containing additive, dominance, maternal effects and sex-dependent expression (Mather and Jinks, 1971; Houle, 1991).

Our aims are (i) to get a better insight into the structure of inheritance of exploration and boldness in a wild bird species, and (ii) to see whether the expression of exploration and boldness depends on offspring sex. We will discuss how our results fit the current theories of the genetic structure and the maintenance of genetic variation in life-history traits.

\section{Materials and methods}

\section{Study system}

The great tit is a very common monogamous territorial passerine, which breeds in secondary holes and artificial nest boxes in all types of wooded areas throughout Europe and parts of Asia and North Africa (Perrins, 1965). From September of the year of fledging onwards, young males start to claim a territory or individual dominance area on vacant ground between the still existing territories of adult males or on less attractive parts of large territories. Early territory ownership is strongly related to survival, reproduction and thus fitness (Drent, 1983). Males are territorial throughout the annual cycle. During autumn and winter, the spatial intolerance is often replaced by hierarchical intolerance during flocking behaviour with other neighbouring territory owners and their mates and nonterritorial birds, particularly when food is locally unpredictable, scarce or difficult to find.

We breed great tits in semi-open aviaries of $2.0 \times 4.0 \times 2.5 \mathrm{~m}^{3}$. Birds are paired up in December and breeding pairs are kept in aviaries from December until the end of the breeding season. From September until December, birds are kept in groups of six to eight individuals per aviary, to mimic natural winter flocking. Juveniles are housed individually in standard cages of $0.9 \times 0.4 \times 0.5 \mathrm{~m}^{3}$ with a wooden bottom, top, sides and rear walls, a wire-mesh front and three perches, as soon as they reach independence. All birds are kept under natural light conditions and have auditory and visual 
contact with other individuals. We feed the captive great tits with a protein rich mixture, and a commercial seed mixture, supplemented daily with mealworms (Tenebrio molitor) or sunflower seeds, while water is provided ad libitum.

\section{Lines and crosses}

All genetic groups (lines and crosses) and their sources used in the analyses are shown in Table 1 . The parental groups $\mathrm{P}_{1}$ and $\mathrm{P}_{2}$ were birds from the fourth generation of selection lines for 'fast' and 'slow' early exploration, respectively (Drent et al, 2003). During these four generations of selection no full or half mate or first cousin matings took place, to keep the level of inbreeding low. To obtain the reciprocal $F_{1}$ crosses $\left(F_{1}\right.$ and $F_{1} R$ in the table), we mated birds from both lines $\left(\mathrm{P}_{1} \times \mathrm{P}_{2}\right.$ and $\mathrm{P}_{2} \times \mathrm{P}_{1}$; in which the female is always the first in the combination) with a total of nine pairs each. Of the available F1 offspring, 36 birds were mated with both $\mathrm{P}$ lines, forming two backcross combinations $\left(B_{1}\right.$ and $\left.B_{2}\right)$ and their reciprocals $\left(B_{1} R\right.$ and $\left.B_{2} R\right)$. For the analyses of sex-dependent expression, the $F_{1}$ and $F_{1} R$ crosses were split up into males (F1m and $\left.F_{1} R m\right)$ and females $\left(F_{1} f\right.$ and $\left.F_{1} R f\right)$. Since we did not have the sex of all individuals, F1m and $F_{1} f$, and $F_{1} R m$ and $F_{1} R f$, do not add up to $F_{1}$ and $F_{1} R$, respectively.

To avoid the effects caused by the parental environment as much as possible, eggs were collected daily before $0900 \mathrm{~h}$, and replaced with dummy eggs. Eggs were stored in a separate room, in a machine that turned the eggs every $2 \mathrm{~h}$. Full clutches were exchanged with clutches of wild females in natural field populations. Breeding in the aviaries is synchronous to breeding in the natural populations. Nestlings were collected from the foster nests at an age of 10 days and then hand reared until independence in the lab (for details of hand rearing, see Drent et al, 2003). We tested birds of all groups 35 days after hatching, as described below.

\section{Tests}

To measure the early exploratory behaviour score (exploration and boldness), we performed two types of behavioural tests: A novel environment test, conducted

Table 1 Sources of the groups (genetic lines and crosses) used in the analyses

\begin{tabular}{cll}
\hline Groups & $\mathrm{N}$ & Source \\
\hline Lines & & \\
$\mathrm{P}_{1}$ & 31 & Fourth generation of the 'fast' line \\
$\mathrm{P}_{2}$ & 35 & Fourth generation of the 'slow' line \\
Crosses & Offspring from \\
$\mathrm{F}_{1}$ & 44 & $\mathrm{P}_{1}$ females $\times \mathrm{P}_{2}$ males \\
$\mathrm{F}_{1} \mathrm{~m}$ & 22 & males from $\mathrm{P}_{1}$ females $\times \mathrm{P}_{2}$ males \\
$\mathrm{F}_{1} \mathrm{f}$ & 15 & females from $\mathrm{P}_{1}$ females $\times \mathrm{P}_{2}$ males \\
$\mathrm{F}_{1} \mathrm{R}$ & 12 & $\mathrm{P}_{2}$ females $\times \mathrm{P}_{1}$ males \\
$\mathrm{F}_{1} \mathrm{Rm}$ & 4 & males from $\mathrm{P}_{2}$ females $\times \mathrm{P}_{1}$ males \\
$\mathrm{F}_{1} \mathrm{Rf}$ & 4 & females from $\mathrm{P}_{2}$ females $\times \mathrm{P}_{1}$ males \\
$\mathrm{F}_{1}$ & 56 & combined $\mathrm{F}_{1}$ and $\mathrm{F}_{1} \mathrm{R}$ \\
$\mathrm{B}_{1}$ & 0 & $\mathrm{P}_{1}$ females $\times \mathrm{F}_{1}$ males \\
$\mathrm{B}_{1} \mathrm{R}$ & 6 & $\mathrm{~F}_{1}$ females $\times \mathrm{P}_{1}$ males \\
$\mathrm{B}_{2}$ & 7 & $\mathrm{P}_{2}$ females $\times \mathrm{F}_{1}$ males \\
$\mathrm{B}_{2} \mathrm{R}$ & 17 & $\mathrm{~F}_{1}$ females $\times \mathrm{P}_{2}$ males \\
\hline
\end{tabular}

$N=$ number of individuals per group. in a standard observation room (analogous to an open field test Walsh \& Cummins, 1976) was followed by two tests of the reaction to different novel objects conducted in the home cage (Drent et al, 2003). The combination of the novel environment score (further referred to as exploration) and the novel object test score (further referred to as boldness) is referred to as early exploratory behaviour (EEB). EEB was used as the selection criterion in the bi-directional selection experiment of Drent et al (2003). The exploration test was carried out between 30 and 35 days after hatching, the boldness tests 10 and 12 days later.

For the exploration test, five tree-like models (further referred to as trees) were placed in an observation room of $4.0 \times 2.4 \times 2.3 \mathrm{~m}^{3}$ (Dingemanse et al, 2002; Drent et al, 2003). The time a bird needed to visit the fourth tree was converted linearly to a scale of $0-10$. Birds who reached the fourth tree within $1 \mathrm{MIN}$ were given a score of 10 , birds that reached the fourth tree within 2 min were given a score of 9 , etc. Birds that did not reach the fourth tree within $10 \mathrm{~min}$, received a score of zero. The result of each boldness test was converted linearly to a $0-5$ scale, with a score of five when a bird pecked the object and a score of zero when the bird did not reach the perch on which the object was placed within 120 s. The scores for the two novel objects were summed giving a total score of $0-10$. The sum of the exploration and the boldness test scores gives the EEB score (Drent et al, 2003; for more details on the tests see Verbeek et al, 1994).

\section{Scaling}

To study the relative levels of variation, it is necessary to know whether any differences are simply a consequence of scale (eg Houle, 1992). Our exploration test is measured in a score that has been converted from a time axis, while our boldness score is converted from a combined time and proximity axis. To be reliable, a scale should be chosen, where the variance is independent of the mean, in which case significant differences in observed levels of variance between samples (ie groups) must be attributable to other factors than differences in the mean (Falconer and Mackay, 1996; Lynch and Walsh, 1998). Since the variance increased with the mean in the exploration test and decreased with the mean in the boldness test, the data had to be rescaled. A simple log transformation, as often used in behavioural characters (Falconer and Mackay, 1996; Stirling et al, 2002), is therefore insufficient.

For optimal scaling we used the procedure CATREG, version 1.0 by DTSS, which is available in the statistical package SPSS 10.1 for Windows. CATREG uses categorical regression with optimal scaling, which quantifies categorical data by assigning numerical values to the categories (ie scores), resulting in an optimal linear regression equation for the transformed variables. The procedure treats quantified categorical variables in the same way as numerical variables. Using nonlinear transformations allow variables to be analysed at a variety of levels to find the best-fitting model. CATREG was applied only on the scores of the original lines. Applying it on all groups would artificially lower all variance components other than additive variance. The original scores of all birds (original lines and crosses and backcrosses) were then replaced by the computed scores. 
Although the analysis with the scaled data changed the exact values of the model parameters, the overall conclusions would have been the same had the analysis been carried out on the original data.

\section{Analysis of group means}

The observed group means were analysed following the methods of Mather and Jinks (1971). The observed exploration, boldness and EEB means of the groups were used to estimate parameters, errors and $\chi^{2}$ values of an initial model, using weighted least-squares methods (for details, see Mather and Jinks, 1971; Kearsey and Pooni, 1996; (Starmer et al, 1998 or Gilchrist and Partridge, 1999)). This initial model consisted of an overall mean $m$ and additive [a] and dominance [d] genetic effects (following the notation of Mather and Jinks, 1971; Kearsey and Pooni, 1996). The estimated parameters were then used to calculate expected group means, For each group, the difference between the observed and the expected group means together with the weight values of the group means, was used to calculate a contribution value for the $\chi^{2}$. All contribution values added up to the $\chi^{2}$ value, with the number of group means minus the number of estimated parameters, as the number of degrees of freedom. A significant $\chi^{2}$ would indicate that the expected group means, generated through the model, significantly deviate from the observed group means. This would imply that the model insufficiently describes the observed means.

Adding the parameters of interest to the initial model produces an extended model. We calculated parameter estimates (with standard error) and expected group means as described above. To test whether added parameters in the extended model increased the fit of the model significantly compared to the initial model, we used a likelihood-ratio test (Lynch and Walsh, 1998). A $t$-test was used to test the significance of the parameter estimates, with the degrees of freedom being the total number of offspring used in the model minus one (Zar, 1999). The significance of the added parameters indicated which parameters could be omitted to simplify the model, where we started with the least significant parameter. When parameters were omitted, the goodness of fit was recalculated. We repeated omitting parameters until the goodness of fit decreased significantly by omitting one more parameter. The model that results from this is referred to as the minimal adequate model.

Three sets of two different models were considered. In the first model (model A) we used the original lines and the reciprocal $F_{1}$, where the male and female $F_{1}$ offspring were treated as two groups, to calculate whether or not the expression of EEB, exploration and boldness is sexdependent. In the second model we used the original parental lines, the reciprocal $\mathrm{F}_{1}$ and the reciprocal backcrosses to test whether an additive maternal effect $\left([a]_{\mathrm{m}}\right\}$ and a dominance maternal effect $\left([d]_{\mathrm{m}}\right)$ are involved in the inheritance of EEB, exploration and boldness. Each model (A and B) was constructed for exploration, boldness and EEB separately, giving a total of six models. The parameter coefficients that we used for the two models are given in Table 2.

To test whether parameter estimates differed significantly from each other, $t$-tests were used (Zar, 1999, p. 124). We performed several $t$-tests, so a Bonferroni correction would be appropriate for hypothesis testing, as the chance of a significant result increases with the number of tests. Since we did not formally test hypotheses, we did not perform a Bonferroni correction and present original $P$-values.

\section{Results}

The observed group means (scaled) used in both models are shown in Table 3. For all traits (exploration, boldness, EEB) separately, expected group means were calculated from a simple genetic model containing a grand mean $(m)$ and an additive component $([a])$ only (maximumlikelihood additive model). The observed group means and the regression lines on the expected group means derived from this maximum-likelihood additive model for all traits are plotted in Figure 1. In no case did this model describe the observed means adequately (minimum $\left.\chi^{2}=8.20 ; P<0.05\right)$.

In a first extended model (model $\mathrm{A}$ ), means were calculated for the separate sexes of the reciprocal $F_{1}$. An initial model was made in the form TRAIT $=m+[a]+[d]$ To test whether the expression of exploration, boldness and EEB is sex dependent, we used group means and their standard errors of the original 'fast' and 'slow' lines and the reciprocal $F_{1}$. This model described the observed means adequately in the cases of exploration and EEB, but not boldness (Table 4, model A). Both $[a]$ and $[d]$ contributed significantly in all models. As $m$ was scaled around 0 , the grand mean is expected to be, and was, equal to zero in all cases. To test sex dependence, this parameter was added to the model. In all cases this was done together with a maternal additive parameter $\left([a]_{\mathrm{m}}\right)$, since the observed mean of the $\mathrm{F}_{1}$ differed from the mean of the $F_{1} R$ cross, in boldness $\left(t_{42.6}=2.674, P<0.05\right)$. The means did not differ significantly from each other in exploration and EEB, respectively $\left(t_{50}=0.281, P=0.78\right.$; $\left.t_{42}=0.971, P=0.34\right)$. The parameter estimate for $[a]_{\mathrm{m}}$ was not significant in either exploration or EEB when running the models in the form TRAIT $=m+$ $[a]+[d]+[a]_{\mathrm{m}}+[$ sde $]$, but it was significant in boldness (Table 4, model A). So to test sex-dependent expression, $[a]_{\mathrm{m}}$ was included in the model of boldness, but not in

Table 2 The parameter coefficients used in model A and B

\begin{tabular}{lrrrrrrr}
\hline & $\mathrm{N}$ & $\mathrm{m}$ & {$[\mathrm{a}]$} & {$[\mathrm{d}]$} & {$[\mathrm{a}]_{m}$} & {$[\mathrm{~d}]_{m}$} & [sde] \\
\hline $\mathrm{P}_{1}$ & 31 & 1 & 1 & 0 & 1 & 0 & 0 \\
$\mathrm{P}_{2}$ & 35 & 1 & -1 & 0 & -1 & 0 & 0 \\
$\mathrm{~F}_{1}$ & 44 & 1 & 0 & 1 & 1 & 0 & \\
$\mathrm{~F}_{1} \mathrm{~m}$ & 22 & 1 & 0 & 1 & 1 & & 1 \\
$\mathrm{~F}_{1} \mathrm{f}$ & 15 & 1 & 0 & 1 & 1 & & -1 \\
$\mathrm{~F}_{1} \mathrm{R}$ & 12 & 1 & 0 & 1 & -1 & 0 & \\
$\mathrm{~F}_{1} \mathrm{Rm}$ & 4 & 1 & 0 & 1 & -1 & & 1 \\
$\mathrm{~F}_{1} \mathrm{Rf}$ & 4 & 1 & 0 & 1 & -1 & & -1 \\
$\mathrm{~B}_{1}$ & 0 & 1 & 0.5 & 0.5 & 1 & 0 & \\
$\mathrm{~B}_{1} \mathrm{R}$ & 6 & 1 & 0.5 & 0.5 & 0 & 1 & \\
$\mathrm{~B}_{2}$ & 7 & 1 & -0.5 & 0.5 & -1 & 0 & \\
$\mathrm{~B}_{2} \mathrm{R}$ & 16 & 1 & -0.5 & 0.5 & 0 & 1 & \\
\hline
\end{tabular}

$N=$ number of individuals per group, $m=$ group mean $[a]=$ additive genetic component, $[d]=$ genetic dominance component, $[a]_{\mathrm{m}}=$ additive maternal component, $[d]_{\mathrm{m}}=$ dominant maternal component (used in Model B only) and [sde]=sex-dependent component (used in Model A only). 
Table 3 Mean scaled test scores for the parental, cross and backcross groups, with their SEM and with $N=$ number of individuals for EEB, exploration and boldness

\begin{tabular}{|c|c|c|c|c|c|c|c|c|c|}
\hline \multirow[t]{2}{*}{ Group } & \multicolumn{3}{|c|}{$E E B$} & \multicolumn{3}{|c|}{ Exploration } & \multicolumn{3}{|c|}{ Boldness } \\
\hline & Mean & SEM & $\mathrm{N}$ & Mean & SEM & $\mathrm{N}$ & Mean & SEM & 1. \\
\hline$P_{1}$ & 851 & 0.139 & 31 & 991 & 0. & 31 & 0.86 & .116 & \\
\hline$P_{2}$ & -1.639 & 0.136 & 35 & -0.878 & 0.073 & 35 & -0.762 & 0.092 & 5 \\
\hline $\mathrm{F}_{1} \mathrm{f}$ & -0.807 & 0.321 & 13 & -0.243 & 0.294 & 14 & -0.463 & 0.164 & 4 \\
\hline $\mathrm{F}_{1} \mathrm{~m}$ & -1.029 & 0.226 & 20 & -0.332 & 0.186 & 22 & -0.678 & 0.101 & 0 \\
\hline$F_{1}$ & -0.916 & 0.181 & 34 & -0.251 & 0.155 & 40 & -0.601 & 0.088 & 5 \\
\hline$F_{1} R f$ & -1.416 & 0.449 & 4 & -0.485 & 0.467 & 4 & -0.931 & 0.057 & \\
\hline $\mathrm{F}_{1} \mathrm{Rm}$ & -1.294 & 0.49 & 4 & -0.534 & 0.481 & 4 & -0.76 & 0.093 & \\
\hline $\mathrm{F}_{1} \mathrm{R}$ & -1.272 & 0.281 & 10 & -0.341 & 0.268 & 12 & -0.874 & 0.051 & 10 \\
\hline $\mathrm{B}_{1}$ & & & 0 & & & 0 & & & \\
\hline $\mathrm{B}_{1} \mathrm{R}$ & -0.139 & 0.605 & 6 & 0.301 & 0.368 & 6 & -0.44 & 0.29 & \\
\hline$B_{2}$ & -1.279 & 0.305 & 7 & -0.684 & 0.268 & 7 & -0.595 & 0.254 & \\
\hline $\mathrm{B}_{2} \mathrm{R}$ & -0.657 & 0.362 & 16 & -0.105 & 0.252 & 16 & -0.657 & 0.362 & 10 \\
\hline
\end{tabular}

the models of exploration and EEB. In neither of the tests was sex-dependent expression found to be significantly different from zero, and the fit of the models did not increase significantly when sex-dependent expression was added (boldness: $\Delta \chi_{1}^{2}=0.66 ; P=0.42$; exploration: $\Delta \chi_{1}^{2}=0.02 ; P=0.88$; EEB: $\left.\Delta \chi_{1}^{2}=0.04 ; P=0.85\right)$. None of the minimal adequate models were significantly different from the observed means.

In a second model (model B), the observed means of all available groups were used to estimate the additive $\left([a]_{\mathrm{m}}\right)$ and dominant-maternal effect $\left([d]_{\mathrm{m}}\right)$. A new base model was made, in the form TRAIT $=m+[a]+[d]$, with the means of all available lines and crosses $\left(\mathrm{P}_{1}, \mathrm{P}_{2}, \mathrm{~F}_{1}\right.$, $\left.F_{1} R, B_{1}, B_{2}, B_{2} R\right)$. Since sex-dependent expression was not significant in model $\mathrm{A}$, all groups were combined for sexes. Again, the initial model adequately described the observed means in the cases of exploration and EEB, but this was not the case for boldness (Table 4, model B). The additive and the genetic dominance parameter were significant in all models. To these models, the maternal parameters were added, so a model was formed, in the form TEST $=m+[a]+[d]+\left[a_{\mathrm{m}}\right]+\left[d_{\mathrm{m}}\right]$. In all cases $d_{\mathrm{m}}$ was the least significant parameter and the fit did not increase in comparison to the same models without $d_{\mathrm{m}}$ (boldness: $\Delta \chi_{1}^{2}=0.55, P=0.46$; exploration: $\Delta \chi_{1}^{2}=0.19$, $P=0.66$; EEB: $\Delta \chi_{1}^{2}=0.13, \mathrm{P}=0.72$ ). After removing $d_{\mathrm{m}}$, all other parameters were significant in the boldness model. Removing $a_{\mathrm{m}}$ from this model would significantly decrease the fit of the model $\left(\Delta \chi_{1}^{2}=9.91, P<0.005\right)$, and the maternal effect was relatively small, being about $1 / 4$ of the additive effect. Removing $a_{\mathrm{m}}$ from this model did not significantly decrease the fit of the model for both exploration or EEB models (exploration: $\Delta \chi_{1}^{2}=0.27$, $P=0.60$; EEB: $\left.\Delta \chi_{1}^{2}=0.40, P=0.53\right)$. This does not automatically mean that the results for the two tests and the combined test are different. The additive maternal parameter of boldness does not differ significantly from either that of exploration $\left(t_{137}=0.87, P=0.39\right)$ or of EEB $\left(t_{137}=0.78, P=0.44\right)$, which indicates that the difference was rather in power than in the strength of the effect. Removing any of the other (all significant) parameters would decrease the fit significantly in these models. All expected means generated through the minimal adequate models were not significantly different from the
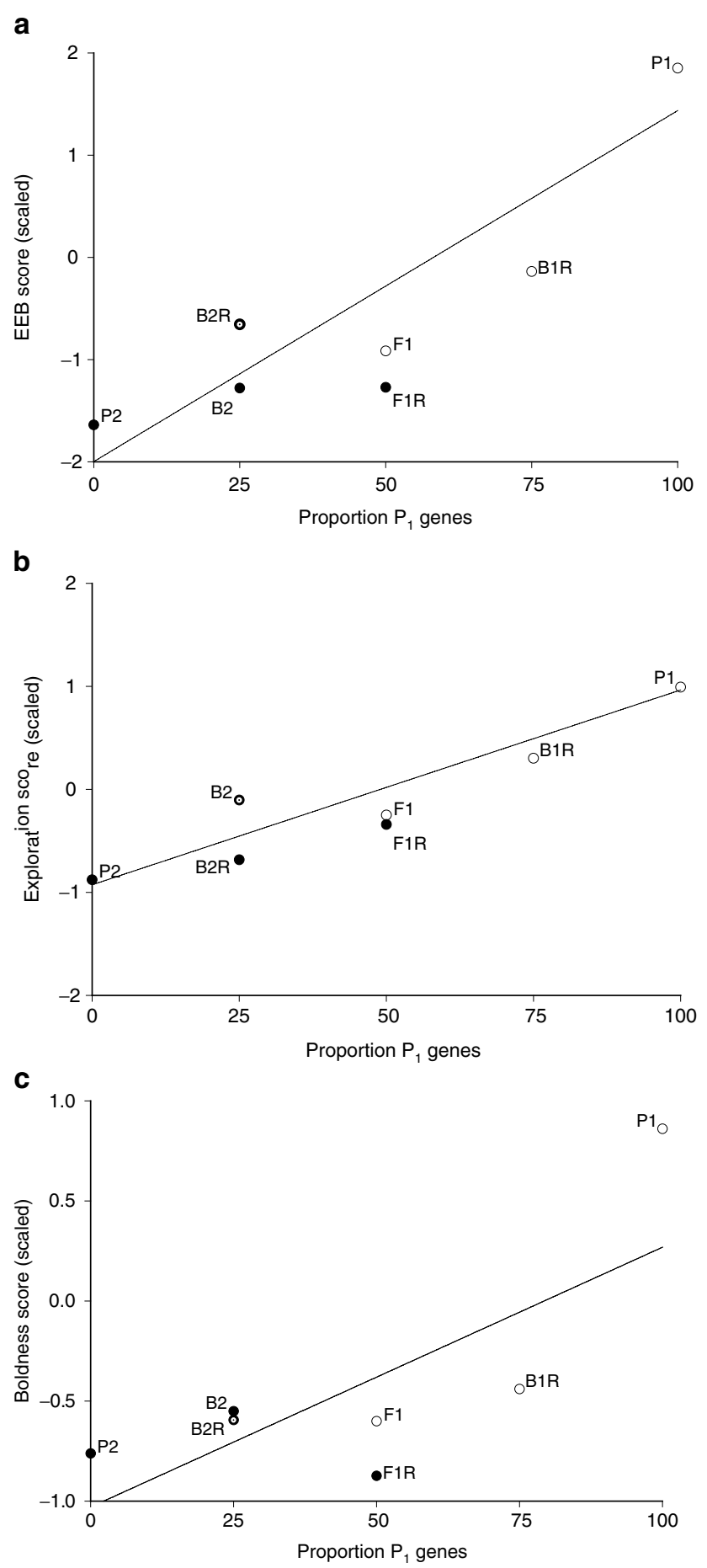

Figure 1 Mean observed test score of the lines and crosses, for EEB (a), exploration (b) and boldness (c). Cytoplasm origin of the lines are indicated with: $O=\mathrm{P}_{1}$ cytoplasm; $\bullet=\mathrm{P}_{2}$ cytoplasm; $\bullet=$ group is a mix of individuals with $\mathrm{P}_{1}$ and individuals with $\mathrm{P}_{2}$ cytoplasm. For reasons of clarity, mean values are plotted without standard errors. The lines are the regression lines based on the expected means.

observed means (Table 4, model B). The dominance effect is best seen in the $F_{1}$ and $F_{1} R$ crossings in Figure $1 a, b$ and $c$. The mean values all lie beneath the regression line of the additive model, which indicates a dominance effect in the direction of the 'slow' line. The strength of 
Table 4 Estimates of composite genetic effects underlying difference in EEB, exploration and boldness

\begin{tabular}{|c|c|c|c|c|c|c|}
\hline & \multicolumn{3}{|c|}{ Model A } & \multicolumn{3}{|c|}{ Model B } \\
\hline & $E E B$ & Exploration & Boldness & $E E B$ & Exploration & Boldness \\
\hline$m$ & $0.106 \pm 0.097$ & $0.057 \pm 0.044$ & $0.049 \pm 0.074$ & $0.174 \pm 0.095$ & $0.063 \pm 0.044$ & $0.051 \pm 0.072$ \\
\hline$[a]$ & $1.745 \pm 0.097^{* * *}$ & $0.935 \pm 0.044^{* * *}$ & $0.696 \pm 0.092^{* * *}$ & $1.661 \pm 0.095^{* * *}$ & $0.927 \pm 0.044^{* * *}$ & $0.639 \pm 0.087^{* * *}$ \\
\hline$[d]$ & $-1.158 \pm 0.188^{* * *}$ & $-0.400 \pm 0.149^{* *}$ & $-0.839 \pm 0.101^{* * *}$ & $-1.024 \pm 0.178^{* * *}$ & $-0.292 \pm 0.136^{*}$ & $-0.784 \pm 0.089^{* * *}$ \\
\hline$[a]_{\mathrm{m}}$ & $0.202 \pm 0.190$ & $0.101 \pm 0.185$ & $0.133 \pm 0.049^{* *}$ & $0.226 \pm 0.154$ & $0.102 \pm 0.141$ & $0.137 \pm 0.050^{* *}$ \\
\hline$[d]_{\mathrm{m}}$ & & & & $-0.330 \pm 0.328$ & $-0.317 \pm 0.221$ & $-0.155 \pm 0.198$ \\
\hline [sde] & $-0.113 \pm 0.330$ & $-0.047 \pm 0.303$ & $0.077 \pm 0.090$ & & & \\
\hline Df & 3 & $\overline{3}$ & $\overline{2}$ & 4 & 4 & 3 \\
\hline$\chi^{2}$ & 1.494 & 0.369 & 3.704 & 7.651 & 3.586 & 4.267 \\
\hline
\end{tabular}

$m=$ group mean, $[a]=$ additive genetic component, $[d]=$ genetic dominance component, $[a]_{\mathrm{m}}=$ additive maternal component, $[d]_{\mathrm{m}}=$ dominant maternal component and [sde] = sex-dependent component. The probabilities of the estimates refer to the $t$-test.

*Significant at the 0.05 level.

** Significant at the 0.01 level.

***Significant at the 0.001 level.

the dominance effect lies between one and $1 / 3$ times the additive effect. The maternal effect is best seen in the difference between $F_{1}$ and $F_{1} R$, and $B_{1}$ and $B_{1} R$. A difference between these means, where the white has the highest value, would indicate that the scores of the offspring of a particular pair are more dependent on the score of the female than on the score of the male.

\section{Discussion}

Our results demonstrate that substantial additive and dominance effects are present in both the exploration test and the boldness test, and in the combination of the test scores. In the last decades, the assumption that there is little or no additive genetic variation in traits that influence fitness, has been under discussion (Frank and Slatkin, 1992). Controversy has arisen about implicit assumptions and interpretations of Fisher's 'Fundamental Theorem of Natural Selection' (Fisher, 1930). Price and Schluter (1991) and Houle (1992) showed that low heritabilities in fitness-related traits are not automatically caused by low amounts of additive genetic variation, but rather by a high residual variance. Estimates of the additive genetic component turned out not to be different from those in morphological traits, when expressed as a fraction of the mean value. Moreover, it is perhaps unreasonable to assume that selection will constantly act in one direction in variable environments (Roff, 1997). The net selection pressure over a longer time might therefore be low. Existing genetic variation available for adaptation may be protected from selection by fluctuating selection pressures. Examples of this are antagonistic pleiotropy or frequency-dependent selection (Wilson et al, 1994). But alternative theories like selectionmutation equilibrium may also be plausible causes for the maintenance of additive genetic variation in avian personalities (Mousseau and Roff, 1987; see Roff, 1997).

Merilä and Sheldon (1999) pointed out that dominance variance is an important variance component in selection studies. Our results show a substantial dominance effect. Quantitative genetic theory predicts that the relative amount of genetic dominance variation should increase under selection (see Introduction). The combination of the presence of both additive and nonadditive variation in our study could thereby be explained through the existence of substantial selection pressures on these traits, but in variable directions. A strong dominance effect is more likely to occur in traits where variation is due to a relatively low number of variable loci. However, our results have to be seen in the right context. The lines used for the crosses have been selected for four generations with a small population size, and our results are therefore dependent on the animals chosen for the selection experiment. This implies that extrapolations from these results could be unreliable (Hill, 1977).

Significant heritabilities of personalities in great tits are found both in the laboratory (Drent et al, 2003; Van Oers et al, 2003) and in natural populations (Dingemanse et al, 2002). Since $h^{2}$ represents the ratio of additive genetic variance to total phenotypic variance, and environmental variance is smaller in the laboratory than in field populations, laboratory estimates of heritabilities possibly overestimate natural heritabilities (Riska et al, 1989). Studies show, however, that laboratory estimates provide reasonable estimations of magnitude and significance of heritabilities in the wild (Riska et al, 1989; Weigensberg and Roff, 1996), but any difference may depend on the maternal and dominance effects (Blanckenhorn, 2002). The fact that the laboratory estimate of the realised heritability derived from a regression on the cumulative response to selection as a function of the cumulative selection differential $\left(h^{2}=0.54\right.$ Drent et al, 2003) is about twice the estimate of heritability derived from the parentoffspring regressions in natural populations $\left(h^{2}=0.34\right.$ Dingemanse et al, 2002) could possibly be caused by the large dominance effect found in this study (Blanckenhorn, 2002). These heritabilities, however, did not differ significantly.

We found no evidence for sex-dependent expression of either of the traits, which is a surprising finding since sex dependant expression is reported in extraversion in humans (Costa et al, 2001). Extraversion is classified as boldness in non-human animals (Budaev, 1999). Other personality traits like aggression in mice are clearly differently expressed in both sexes (Benus, 2001; Sluyter, 1994). In humans, sex differences are found in the main personality axes Agreeableness, Neuroticism and Extraversion. Both biological and social psychological theories try to explain the existence of gender differences in personalities. Some biological theories predict that sex- 
dependent expression in personality traits arise from innate temperamental differences between the sexes, evolved by natural selection (Costa et al, 2001). Evolutionary psychology predicts that sexes will differ in domains in which they have faced different adaptive problems throughout evolutionary history (Buss, 1995). These are confirmed by some other biological theories, which point to hormonal differences and their effects on personality. Studies on human personalities confirm that the sex differences in androgens during development, cause differences in interests, activities and aggression (Berenbaum and Resnick, 1997; Berenbaum, 1999).

The presence of an additive maternal component in boldness and not in exploration was the only difference we found in the analysed traits. The calculated estimated additive maternal parameters for the different traits are not, however, significantly different from each other, which indicates an effect of the small sample size, and we recognise that, with including the additive maternal parameter, we have reached the limits of the detection ability of the experimental design. The significant maternal component in boldness suggests that maternal effects are likely to play a role in both exploration and boldness. Since we collected the eggs just after laying, the most plausible maternal influence would be through the deposition of substances (eg maternal hormones) in the egg. Our results show that phenotypic expression is likely to be influenced by maternal hormones, but that this is independent of the offspring sex.

Our sample size was relatively small, which is a general problem in these kinds of experiments. Since the betweenline variance is highly dependent on the withinline variance, we would expect interpretation problems when the withinline variances increase rapidly. This increase in withinline variance depends mainly on the number of chromosomes and the map length (Hill, 1977) and less on the population size. Since the number of chromosomes in birds is relatively high, we expect that our initial population size of 18 birds gave us enough power to detect effects that exceed $1 / 5$ of the additive effect.

Although there is no evidence yet for a direct relationship between fitness and personalities, evidence is accumulating that personality traits the affect time of breeding, reproduction, survival and dispersal (Armitage, 1986; Réale and Festa-Bianchet, 2003; Dingemanse et al, 2003; Van Oers, 2003). Our study on the genetic structure of avian personality traits show that these traits have a substantial amount of additive genetic variance, a considerable dominance variance, and that sex-dependent expression is absent.

\section{Acknowledgements}

$\mathrm{KO}$ is supported by NWO (grant SLW 805-33-323). We thank Juha Merilä, Kate Lessells and Erik Postma and two anonymous referees for their constructive comments on the manuscript. Piet de Goede did a great part of the fieldwork and helped with testing the birds. We would also like to thank Mary-Lou Aaldering, Tanja Thomas and Janneke Venhorst for taking care of the birds and Christa Kerlen-Mateman for sex determination. Wil Keultjes built most of the experimental set-up. Permission for breeding, cross breeding, testing and blood sampling was granted to $\mathrm{KO}$ by the legal comity 'KNAW Dier Experimenten
Commissie (DEC)'. This is publication number 3219 NIOO-KNAW Netherlands Institute of Ecology.

\section{References}

Armitage KB (1986). Individuality, social behaviour, and reproductive success in yellow-bellied marmots. Ecology 67: 1186-1193.

Armitage KB, Van Vuren DH (2003). Individual differences and reproductive success in yellow-bellied marmots. Ethol Ecol Evol 15: 207-233.

Benus RF (2001). Coping in female mice from lines bidirectionally selected for male aggression. Behaviour 138: 997-1008.

Benus RF, Bohus B, Koolhaas JM, Van Oortmerssen GA (1991). Heritable variation in aggression as a reflection of individual coping strategies. Experientia 47: 1008-1019.

Benus RF, Koolhaas JM, Van Oortmerssen GA (1987). Individual differences in behavioural reaction to a changing environment in mice and rats. Behaviour 100: 105-122.

Berenbaum SA (1999). Effects of early androgens on sex-typed activities and interests in adolescents with congenital adrenal hyperplasia. Horm Behav 35: 102-110.

Berenbaum SA, Resnick SM (1997). Early androgen effects on aggression in children and adults with congenital adrenal hyperplasia. Psychoneuroendocrinology 22: 505-515.

Bernardo J (1996). Maternal effects in animal ecology. Am Zool 36: 83-105.

Blanckenhorn WU (2002). The consistency of quantitative genetic estimates in field and laboratory in the yellow dung fly. Genetica 114: 171-182.

Budaev SV (1999). Sex differences in the Big Five personality factors: testing an evolutionary hypothesis. Pers Indiv Diff 26: 801-813.

Buirski P, Plutchik R, Kellerman H (1978). Sex differences, dominance, and personality in the chimpanzee. Animal Behav 26: 123-129.

Buss DM (1995). Psychological sex differences: origins through sexual selection. Am Psych 50: 164-168.

Carere C (2003). Personalities as an Epigenetic Suite of Traits. A Study on a Passerine Bird. PhD Thesis. University of Groningen, Groningen.

Carere C, Van Oers K (2003). Shy and bold great tits (Parus major): body temperature and breath rate in response to handling stress. Physiol Behav (in preparation).

Carere C, Welink D, Drent PJ, Koolhaas JM, Groothuis TGG (2001). Effect of social defeat in a territorial bird (Parus major) selected for different coping styles. Physiol Behav 73: 427-433.

Costa Jr PT, Terracciano A, Mccrae RR (2001). Gender differences in personality traits across cultures: robust and surprising findings. J Pers Soc Psychol 81: 322-331.

Crnokrak P, Roff DA (1995). Dominance variance: associations with selection and fitness. Heredity 75: 530-540.

Dingemanse NJ (2003). Natural selection and avian personalities in a fluctuating environment. PhD Thesis. University of Utrecht, Utrecht.

Dingemanse NJ, Both C, Drent PJ, Van Oers K, Van Noordwijk AJ (2002). Repeatability and heritability of exploratory behaviour in wild great tits. Anim Behav 64: 929-937.

Dingemanse NJ, Both C, Van Noordwijk AJ, Rutten AL, Drent PJ (2003). Natal dispersal and personalities in great tits (Parus major). Proc R Soc Lond B 270: 741-747.

Drent PJ (1983). The functional ethology of territoriality in the Great Tit (Parus major L.). PhD Thesis. University of Groningen.

Drent PJ, Dingemanse NJ, Van Oers CHJ (2002). Functional significance and heritability in coping strategies in a wild territorial passerine: the great tit. In: Mettke-Hofmann C, Gansloßer U (eds) Bird Research and Breeding, Filander Verlag: Fürth. pp 25-46.

Drent PJ, Marchetti C (1999). Individuality, exploration and foraging in hand raised juvenile great tits. In: Adams NJ, 
Slotow RH (eds) Proceedings of the 22nd International Ornithological Congress, Durban, Birdlife South Africa: Johannesburg. pp 896-914.

Drent PJ, Van Oers K, Van Noordwijk AJ (2003). Realized heritability of personalities in the great tit (Parus major). Proc $R$ Soc Lond B 270: 45-51.

Eising CM, Eikenaar C, Groothuis TGG (2001). Maternal androgens in black-headed gull (Larus ridibundus) eggs: consequences for chick development. Proc $R$ Soc Lond $B$ 268: 839-846.

Falconer DS, Mackay TFC (1996). Introduction to Quantitative Genetics, Longman: New York.

Fisher RA (1930). The Genetical Theory of Natural Selection, Oxford University Press: Oxford.

Frank SA, Slatkin M (1992). Fishers fundamental theorem of natural selection. TREE 7: 92-95.

Gilchrist AS, Partridge L (1999). A comparison of the genetic basis of wing size divergence in three parallel body size clines of Drosophila melanogaster. Genetics 153: 1775-1787.

Gosling SD (2001). From mice to men: What can we learn about personality from animal research? Psychol Bull 127: 45-86.

Greenberg R, Mettke-Hofmann C (2001). Ecological aspects of neophobia and neophilia in birds. In: Nolan Jr V, Thompson CF (eds) Current Ornithology 16, Plenum Press: New York. pp 119-178.

Heeb P, Werner I, Kölliker M, Richner H (1998). Benefits of induced host responses against an ectoparasite. Proc $R$ Soc Lond B 265: 51-56.

Hessing MJC, Hagelso AM, Van Beek JAM, Wiepkema PR, Schouten WGP, Krukow R (1993). Individual behavioral characteristics in pigs. Appl Anim Behav Sci 37: 285-295.

Hill WG (1977). Variation in response to selection. In: Pollak E, Kempthorne O, Baily Jr TB (eds) Proceedings of the International Conference on Quantitative Genetics. August 16-21, 1976, The Iowa State University Press: Ames. pp 343-365.

Houle D (1991). Genetic covariance of fitness correlates - what genetic correlations are made of and why it matters. Evolution 45: 630-648.

Houle D (1992). Comparing evolvability and variability of quantitative traits. Genetics 130: 195-204.

John OP (1990). The 'big-five' factor taxonomy: dimensions of personality in the natural language abd in questionnaires. In: Pervin LA (ed) Handbook of Personality: Theory and Research, Guilford Press: New York. pp 66-100.

Jones JS (1987). The heritability of fitness: bad news for good genes? TREE 2: 35-38.

Kearsey MJ, Pooni HS (1996). The Genetical Analysis of Quantitative Traits, Chapman \& Hall: London.

Komdeur J, Daan S, Tinbergen JM, Mateman C (1997). Extreme adaptive modification in sex ratio of the Seychelles warbler's eggs. Nature 385: 522-525.

Lynch M, Walsh B (1998). Genetics and Analysis of Quantitative Traits, Sinauer Associates, Inc.: Sunderland, MA.

Marchetti C, Drent PJ (2000). Individual differences in the use of social information in foraging by captive Great Tits. Animal Behav 60: 131-140.

Mather K, Jinks JL (1971). Biometrical Genetics. The Study of Continuous Variation, Chapman \& Hall Ltd: London.

Mcadam AG, Boutin S, Réale D, Berteaux D (2002). Maternal effects and the potential for evolution in a natural population of animals. Evolution 56: 846-851.

Merilä J, Sheldon BC (1999). Genetic architecture of fitness and nonfitness traits: empirical patterns and development of ideas. Heredity 83: 103-109.

Merilä J, Sheldon BC (2000). Lifetime reproductive success and heritability in nature. Am Nat 155: 301-310.

Merilä J, Sheldon BC (2001). Avian quantitative genetics. In: Nolan Jr V (ed) Current Ornithology 16, Kluwer Academic/ Plenum Publishers: New York. pp 179-255.
Mousseau TA, Fox CW (1998). The adaptive significance of maternal effects. TREE 13: 403-407.

Mousseau TA, Roff DA (1987). Natural selection and the heritability of fitness components. Heredity 59: 181-197.

Perrins CM (1965). Population fluctuations and clutch-size in the Great Tit, Parus major. I Animal Ecol 34: 601-647.

Price T, Schluter D (1991). On the low heritability of life-history traits. Evolution 45: 853-861.

Réale D, Festa-Bianchet M (2000). Quantitative genetics of life-history traits in a long-lived wild mammal. Heredity $\mathbf{8 5}$ 593-603.

Réale D, Festa-Bianchet M (2003). Predator-induced natural selection on temperament in bighorn ewes. Animal Behav 65 463-470.

Réale D, Gallant BY, Leblanc M, Festa-Bianchet M (2000). Consistency of temperament in bighorn ewes and correlates with behaviour and life history. Animal Behav 60: 589-597.

Riska B, Prout T, Turelli M (1989). Laboratory estimates of heritabilities and genetic correlations in nature. Genetics 123: 865-871.

Roff DA (1997). Evolutionary Quantitative Genetics. Chapman \& Hall: New York.

Schwabl H, Mock DW, Gieg JA (1997). A hormonal mechanism for parental favouritism. Nature 386: 231

Sheldon BC, Andersson S, Griffith SC, Rnborg J, Sendecka J (1999). Ultraviolet colour variation influences blue tit sex ratios. Nature 402: 874-877.

Sluyter F (1994). Y chromosome, aggression and coping. PhD Thesis. University of Groningen, Groningen.

Starmer WT, Polak M, Wolf LL, Barker JSF (1998). Reproductive characteristics of the flower breeding Drosophila hibisci bock (Drosophilidae) in eastern Australia: genetic and environmental determinants of ovariole number. Evolution 52: 806-815.

Stearns SC (1992). The Evolution of Life Histories, Oxford University Press: Oxford.

Stirling DG, Réale D, Roff DA (2002). Selection, structure and the heritability of behaviour. J Evol Biol 15: 277-289.

Van Noordwijk AJ (1990). The methods of genetical ecology applied to the study of evolutionary change. In: Wöhrmann K, Jain SK (eds) Population Biology: ecological and evolutionary viewpoints, Springer Verlag: Berlin. pp 291-319.

Van Oers K (2003). On the genetics of avian personalities: mechanism and structure of behavioural strategies in the great tit (Parus major). PhD Thesis. University of Utrecht, Utrecht.

Van Oers K, Drent PJ, De Goede P, Van Noordwijk AJ (2003). Realized heritability and repeatability of risk taking behaviour in relation to avian personalities. Proc $R$ Soc Lond B 271: 65-73.

Verbeek MEM, Boon A, Drent PJ (1996). Exploration, aggressive behaviour and dominance in pair-wise confrontations of juvenile male great tits. Behaviour 133: 945-963.

Verbeek MEM, De Goede P, Drent PJ, Wiepkema PR (1999). Individual behavioural characteristics and dominance in aviary groups of great tits. Behaviour 136: 23-48.

Verbeek MEM, Drent PJ, Wiepkema PR (1994). Consistent individual differences in early exploratory behaviour of male great tits. Animal Behav 48: 1113-1121.

Walsh RN, Cummins RA (1976). The open-field test: a critical review. Psychol Bull 83: 482-504.

Weigensberg I, Roff DA (1996). Natural heritabilities: Can they be reliably estimated in the laboratory? Evolution 50: 2149-2157.

Wilson DS, Clark AB, Coleman K, Dearstyne T (1994). Shyness and boldness in humans and other animals. TREE 9: 442-446.

Wolf JB, Brodie ED, Cheverud AJ, Moore AJ, Wade MJ (1998). Evolutionary consequences of indirect genetic effects. TREE 13: 64-69.

Zar JH (1999). Biostatistical Analysis, Prentice Hall: New Jersey. 